DOI: $10.2478 / v 10057-009-0003-8$

\author{
KAMILLA BARGIEL-MATUSIEWICZ \\ University of Warsaw \\ ALEKSANDRA BARGIEL-FIRLIT \\ Secondary School no 1, Gierałtowice
}

\title{
CORRECTION TECHNIQUES PREFERRED BY STUDENTS DURING THE PROCESS OF LEARNING A FOREIGN LANGUAGE
}

\begin{abstract}
Mistakes can be seen as an integral and natural part of learning. This is true of the development of a child's first language as well as of second language learning by children and adults. Learning never proceeds without making errors. They appear naturally in linguistic development. The main aim of the research is to find out if and how the learners appreciate error correction. Besides, its goal is to provide qualitative data concerning learners' opinions, as well as bring some comments on errors in their own experience. The research results clearly indicate that students generally believe that making errors is one of the things they do while learning a foreign language. They agree that they can learn a lot from their mistakes. Almost $40 \%$ of the research subjects think that error correction is absolutely necessary, and a half of them see correction as very helpful. They value correction as a means of improvement. Most learners are not afraid of errors and treat them as something natural. However, almost half of the research subjects associate making a mistake with the feeling of guilt. They use an avoidance technique in order not to be laughed at when they make a mistake. Thus, errors should not be approached with hostility. It is better to view errors as the sign of a learner's progress rather than a sign of lack of knowledge.
\end{abstract}

Key words: second language learning, error analysis, error correction, correction techniques

\section{Introduction}

Mistakes can be seen as an integral and natural part of learning. This is true of the development of a child's first language as well as of second language learning by children and adults. Learning never proceeds without making errors. They appear naturally in linguistic development. What is more, all learners make similar errors at comparable stages of language learning (Arabski, 1979; Biederman, 1987; Brala, 2002; Chomsky, 1987; Chaudron, 1988).

Address for correspondence: Kamilla Bargiel-Matusiewicz, University of Warsaw, Faculty of Psychology, Stawki 5/7, 00-183 Warsaw, Poland. E-mail: k.matusiewicz@op.pl 
In the process of second language acquisition the presence of errors is a symptom of the learner's progress through an interlanguage towards a closer and closer approximation to the target language (Whorf, 1969; Wierzbicka, 1980; Ellis, 1994). Errors illustrate the patterns of learners' developing interlanguage systems and show where they have over-generalized a second language rule or where they have inappropriately transferred a first language rule to the second language (Corder, 1981; Lightbown \& Spada, 1993).

The teacher's attitude to errors and correction is central to what is done in the classroom on a day to day basis. The majority of language teachers are interested in the issue of errors and error correction which is very often a subject of vivid discussion. Teachers' familiarity with various types of errors, their awareness of the most frequent ones, and the understanding of the nature of errors make them more sensitive to the problem of error treatment: which ones to correct, when, and how to correct errors so that learners derive the most from them (Albanese, 1999; Dunford, 1993; Jacobs, Michaels, 2007; Johnson, 1995; Kaye, 2000). Thus, the aim of this article is to shed some light on the data concerning students' beliefs about errors and their attitudes towards correction.

Teachers' convictions often include their own strongly held beliefs about the learners' expectations and needs as regards correction. Some teachers claim that learners insist on being corrected whenever an error occurs, others make an opposite claim. Many teachers observe that they significantly modify their own attitude towards the role of error correction as they gain experience. That is to say that, generally, experienced teachers correct less than they used to at the beginning of their professional careers (Cox \& Eyre, 1999; Zybert, 1999).

Persistent errors, especially when they are shared by almost all students in a class, should be brought to the learners' attention. However, teachers ought to bear in mind that excessive error correction may have a strong negative effect on students' motivation.

Just as there are different kinds of errors there are also various ways of correcting them. Depending on who provides the correction a distinction is made between teacher correction, peer correction and self-correction (Zybert, 1999).

The most common form of teacher correction is probably providing a correct model accompanied by an explicit explanation of the error. This form of correction also seems to be the most expected one by the learners in the formal language learning situation.

Peer correction occurs when one learner corrects another one. This kind of correction is appreciated for a number of reasons. Its most important advantages are the following: both learners are involved in face-to-face interaction; the teacher obtains information about learners' current abilities; learners co-operate in language learning and become less teacher-dependent; peer correction does not make errors a public affair, which protects the learners' ego and increases their self-confidence (Higgins, 1987). 
Self-correction is possible when the learner realises that he has committed a mistake and repairs it by providing a correct form in place of the wrong one. Selfcorrection seems to be preferred to correction provided by others: it is face-saving and allows the learner to play an active role in the corrective event (Murray, 1999; Zybert, 1999).

\section{Description of the research}

The main aim of the research is to find out if and how the learners appreciate error correction. Besides, its goal is to provide qualitative data concerning learners' opinions, as well as bring some comments on errors in their own experience. The research will concentrate on students' personal opinions connected with errors: if they are afraid of making mistakes, whether they pay great attention to accuracy while speaking, or if errors do not bother them at all. It will show how learners react to corrective feedback received both from the teacher and from another learner.

Such an investigation carried out in the foreign language classroom can help teachers understand different learner types in the class. Having such data the teacher would be able to adjust his correction methods to students' individual needs.

The research was carried out in four secondary schools in Poland. The subjects were students of grades I - III. They were aged between thirteen and sixteen. The number of students was 316: 161 girls and 155 boys. There were 101 students in the first grade, 106 the second grade, 109 the third grade. Their level of advancement is different: from upper elementary to pre- intermediate depending on their age. Some of them have been learning English for four years, others for seven years, but the majority has been learning English for five years. Their exposure to English at school is the same, as each age group has three hours of English a week. They use the course book entitled Open Doors written by Norman Whitney (published by OUP, 1995).

\section{Research tools and procedures}

The research was carried out by means of a questionnaire. The questionnaire was anonymous, and to avoid misunderstandings, administered in Polish.

The intention of it was to elicit reliable information about the students' emotions connected with the situation when they make a mistake and are corrected. The questionnaire contained some background questions as well as specific questions. There is a group of open-ended questions and close-ended questions.

The questions put emphasis on learners' corrective preferences. Students had to define if they learn from their errors, who they prefer to correct them - the teacher, another student from the class, or, if they prefer to correct their errors themselves. They were also invited to specify in what way they like to be corrected: to be only informed that they made a mistake, to know what kind of error it is, or to get the 
Figure 1. The age of the students

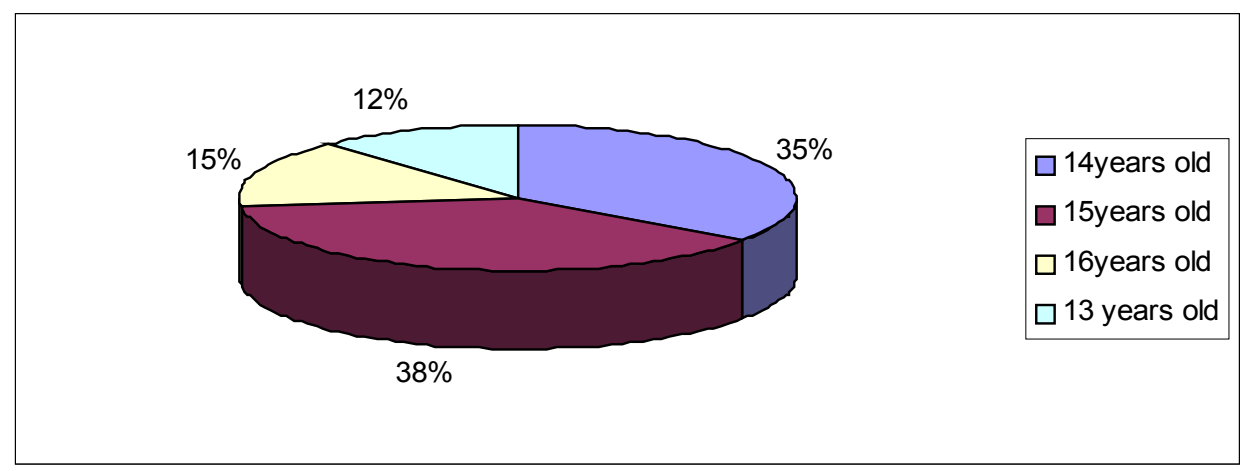

correct form. In addition, students were given questions about their preferred techniques of oral correction and correction of their written work. Finally, they were asked to present their attitude towards discussing their errors in public during the lesson, and to express what their feelings would be in situations when the teacher makes them correct somebody else.

\section{Data presentation and analysis}

The aim of the research was to obtain information about students' attitudes towards error correction and their opinions about the importance of being corrected. It was also intended to achieve objective material which might be useful in the teacher's job, since it is believed that the knowledge of learners' expectations as to error correction leads to improved teaching.

The questionnaire included several background questions. These questions bring information about students' age and sex, as well as about the period of learning English and the number of English lessons they have a week.

Question no 1 concerned learners' age. As can be seen from the Figure 1, 12\% of the subjects were thirteen years old, 35\% were fourteen years old, 38\% were fifteen, and $15 \%$ were sixteen years old.

Question no 2 dealt with learners' gender. As said before, $52 \%$ of the subjects were girls and $48 \%$ were boys. The next question concerned the number of years students had been learning English. The majority of them (57\%) had been learning English for five years, 25\% six years, $10 \%$ seven years, and $7 \%$ for only four years. All of them have three hours of English a week.

\section{Learners' view on correction of errors}

The questionnaire included questions in which students were asked to state if they believe that we learn from errors and to express their attitude towards error 
Figure 2. Students' opinions about error correction

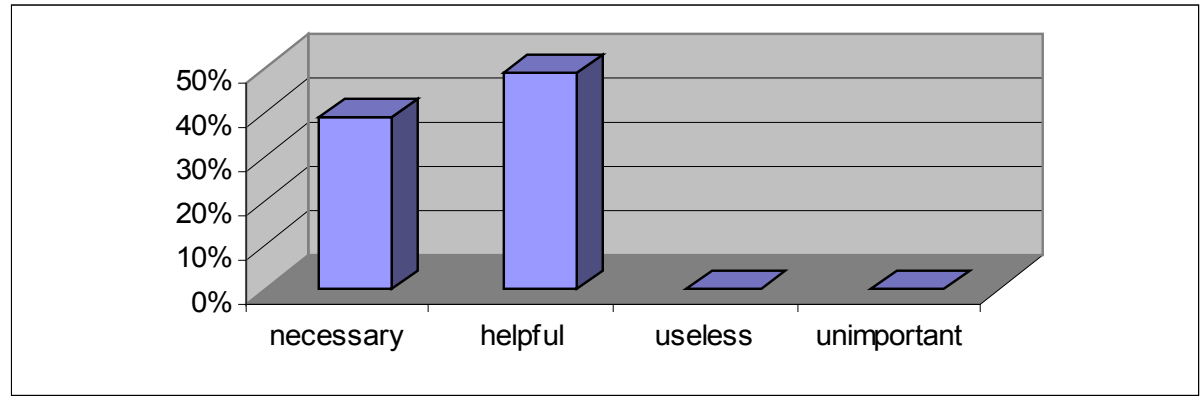

correction. The answer to the first question was 'yes' in $100 \%$. All the students believe that making a mistake is something natural and unavoidable. They are aware of the fact that the lack of errors equals a lack of progress. However, $48 \%$ of those students claim that they are afraid of making errors. Why? The reasons are very different. First, some students make a link between errors and bad marks. When they are not certain if what they are going to say is correct they use an avoidance technique. Secondly, some of them are afraid of being laughed at by other students. Yet, there were some students who could not answer clearly what was the reason of their fear. On the other hand, $52 \%$ of pupils are not afraid of mistakes and treat them as an element in developing language fluency.

The second question brought information concerning the necessity of correction. $39 \%$ of students think that error correction is absolutely necessary in the process of learning a foreign language, and $49 \%$ see correction as very helpful and useful. There was no single answer that correction is unimportant or useless. Figure 2 shows how students perceive correction of their errors.

To sum up, all the students agree that there is no progress without errors and that correction is very significant. Students accept errors as natural and inevitable. All language learners, including first language learners, make errors on the way to attain successive levels of competence.

\section{Students' attitude towards teacher correction}

The question of students' preferences in error correction concerned their recognition of the authority exercised over their errors. They may either accept this authority or reject it. In the traditional models of instruction the teacher's position is necessarily superior with regard to the learner. The teacher has expert knowledge that he/she is trying to transmit to learners. The manner in which the teacher handles the learners' errors determines their attitudes and their receptivity to being corrected. It is also well known that some learners benefit more from self-correction or peer-correction than from the teacher's correction. The potential value of 
Figure 3. Students' corrective preferences

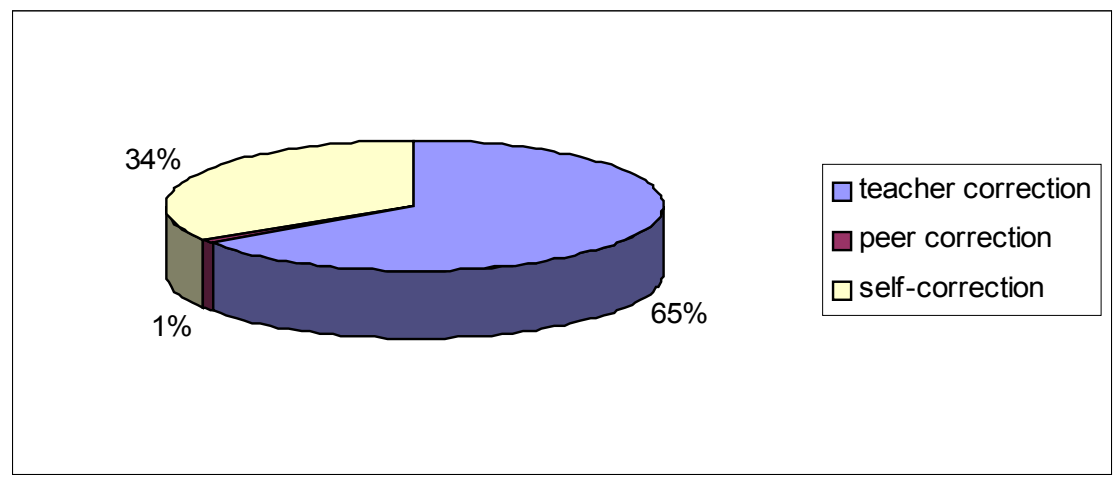

correcting may depend on whom the learner estimates to be the most authoritative corrector: the teacher, oneself or another student.

Teachers note that many learners expect them to correct their errors. Some students count entirely on teacher's help, others need more independence and prefer self-monitoring.

The research shows that the teacher is treated as an authority when it comes to error correction. It can be seen from the Figure 3 that $65 \%$ of students claim the teacher to be the right person to correct them. The number shows that they can rely on the teacher's knowledge and are not afraid of his correction techniques. When they make a mistake they prefer to be corrected by someone with a superior position in the classroom. They believe the teacher's position give him the right to correct learners' errors. Being corrected by other students may bring the feeling of humiliation, especially when one student corrects the other in front of the classroom. The students who are better learners may overuse this technique in order to show off. Such a situation may develop an unhealthy atmosphere in the classroom as well as envy among students. Only one subject said that he liked to be corrected by another student. The conclusion from such data may be that teenagers do not welcome criticism from their peers.

On the other hand, 34\% of students prefer to correct their errors themselves. People attribute greater value to whatever they achieve with effort. Thus, it seems likely that some language learners benefit more from what they notice themselves than from what others tell them. The desire for self-correction may be interpreted as resulting from learner ambition to prove to both the teacher and other learners in the class that he/she is able to deal with imperfections.

When it comes to discussing errors in the classroom, students present various opinions. A large number of them (51\%) do not wish to have their errors discussed in public. This activity can be very stressful for many learners. Stress distracts the 
Figure 4. Students' feelings towards public correction by the teacher

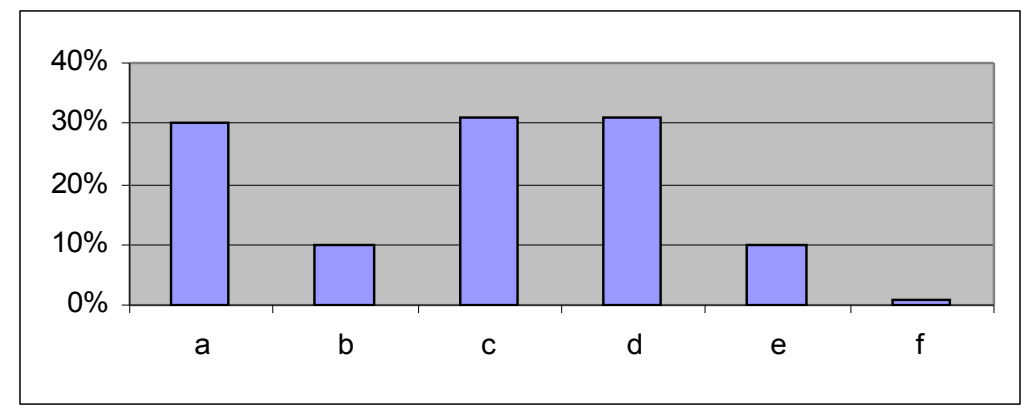

learning process which cannot proceed effectively when learners feel threatened. The most common arguments against open correction given by the research subjects are as follows: 'I don't want the whole class to know about my mistakes'; 'Those are my own failures'; 'I prefer to avoid being laughed at'.

Many students treat errors as a sign of a failure. People would rather have their mistakes gone unnoticed. It is not something we want to share with others. However, $37 \%$ of the subjects are not afraid of raising the topic of their errors in the classroom. They claim that dealing with errors together may have good results. They also believe that bringing some errors to students' attention is a great opportunity to find out the correct form, e.g., the right way to pronounce, or write, a given word. Twenty-three percentage of the learners regard public discussion of errors as very helpful. Owing to having their errors discussed students get a second chance to concentrate on certain language items, to have them explained one more time, and to draw some conclusions. Therefore, thanks to such a careful analysis of errors, many learners do not commit them any longer.

Twelve percentage of the students did not present their point of view concerning discussing their mistakes.

The issue of public and individual correction is brought up again in the next question. This time students expressed what they felt being corrected by the teacher either individually or in front of the classroom. First, in relation to correction in public, learners claim they feel: a. 'comfortable - the teacher does not offend anybody'; b. 'quite good'; c. 'nervous/hesitant'; d. 'ashamed'; e. 'not good'; f. 'humiliated'.

Secondly, in relation to individual correction, learners' remarks are: a. 'I feel very good'; b. 'I'm glad to have my errors corrected'; c. 'I feel comfortable'; d. 'I feel humiliated'.

As can be observed from the Figure 5, students generally have a positive view on teacher's correction. Half of them feel free to discuss their problems with teacher. They appreciate the time teacher devotes for individual consultations. Besides, they do not worry about presenting their errors during lessons. On the other hand, 
Figure 5. Students' feelings towards individual correction by the teacher

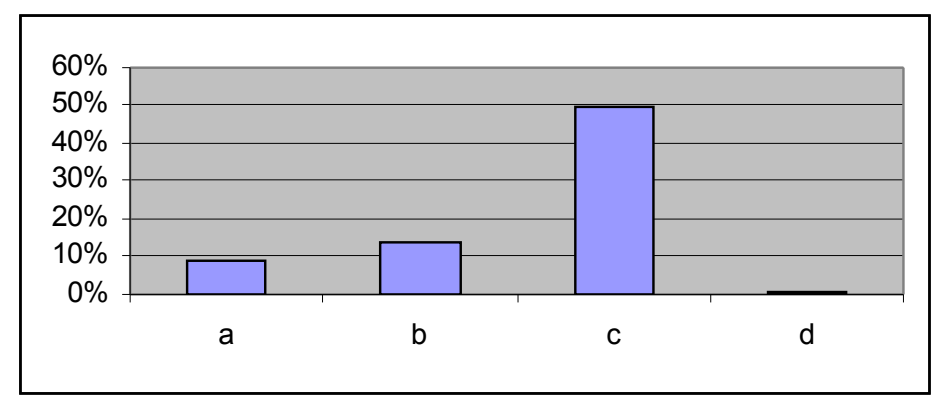

Figure 6. The frequency of teacher's correction

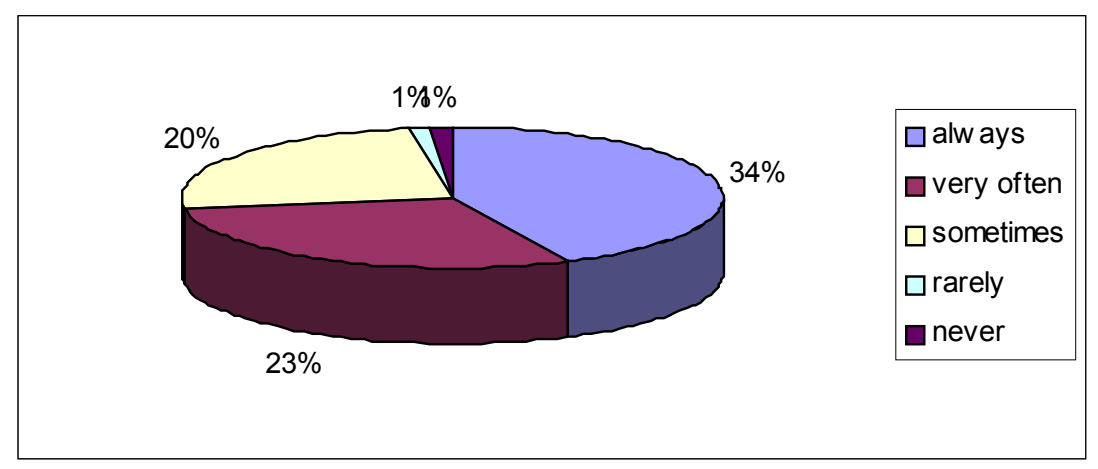

Figure 7. Students' feelings about the occurrence of correction

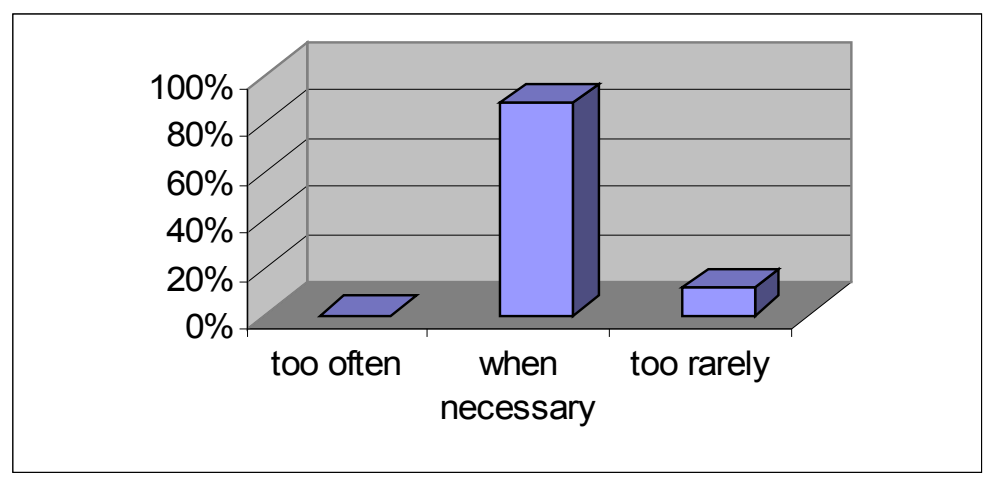


some students do not like being in the public eye. Then they get nervous and feel uneasy. One student even views teacher's correction as humiliating and evoking the feeling of guilt.

Answering question no 11 students noticed that their teacher paid great attention to errors. Forty-nine percentage agree that teacher recognizes mistakes and provides corrective feedback.

Questions no 12 and 23 referred to the frequency of teacher's corrective moves in the classroom.

Figure 6 shows how students perceive the amount of correction of their mistakes.

Most of the students (34\%) claim that the teacher corrects their errors whenever they occur. For $23 \%$ of learners, correction comes across as a very frequent event. Twenty percentage think that the teacher reacts to their mistakes only sometimes, whereas $1 \%$ of subjects say that they are not corrected at all or very rarely.

In addition, in question 23 students justified their attitude towards the amount of correction. The majority (89\%) feel that the teacher corrects them when it is necessary, but $11 \%$ would like to be corrected more often. What is more, no one considers the teacher to overuse correction during lessons. Thus, it can be said that students agree about the importance of correction in the way to achieve language competence.

The results discussed above are presented in the Figure 7.

\section{Correction techniques preferred by students}

As said above, the majority of subjects prefer to be corrected by their teacher. They insist on the teacher correcting them by providing the right form. Many feel they would not be able to repair their errors themselves. Yet, 34\% opt for self-correction.

In order to find out more details in this area the author invited the students to answer a question whether they liked to be asked to correct themselves, and explain why, or why not (que. no 21). The answers confirm that self correction is not the most desirable form of error treatment, but still quite popular. Forty-three percentage agree that self-correction is a chance to re-think and revise the material that is being taught. They like to draw conclusions from their own mistakes. This helps them develop independence in learning. As they take more responsibility for their own errors, they benefit more from them. In general, learners value more what they achieve with effort.

However, $53 \%$ of students do not like to be expected to correct themselves. Most of them say they are usually not sure how to correct their error. In an attempt to repair one error they can make another one. Many students prefer to get some help when it comes to error treatment. They would rather get the correct form and have their mistakes discussed. They need some explanation to deal with their errors successfully. 
Figure 8. Students' feelings towards peer correction in front of the classroom

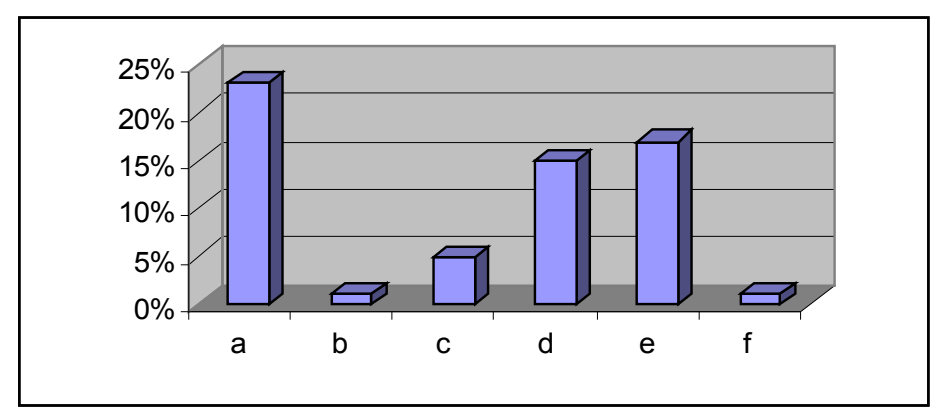

Peer correction appears to be the least popular way of correction among the young people. Very few learners want to be corrected by other learners (only 1\% of students chose this option). Teenagers are very sensitive to criticism from their peers. Yet, they can be very cruel and laugh at others because of their failures. Filling in the questionnaire students pointed to the fact that peer correction can be done with completely different intentions, either to help somebody or to ridicule him or her. Learners who are at the top of the class may try to correct every error they notice in their classmates' utterances. This way they want to show their advantage over their peers. Some students react with laughter when someone finds it difficult to make a correct sentence or pronounce correctly a given word. So not surprisingly the majority of students claim they do not welcome correction from their peers.

The subjects were also asked to express their feelings as regards correction by another student in front of the classroom and individually.

Being corrected in front of the classroom means being the centre of everybody's attention, however, not because of something positive but due to the lack of knowledge.

Students' comments on public correction were as follows: a. 'I feel bad'; b. 'I feel humiliated'; c.I am embarrassed'; d. 'I get nervous'; e. 'I feel quite good'; f. 'the fact that someone knows more than me motivates me to study more'.

Individual peer correction is viewed by learners in a more positive light. When students correct one another individually, the intention is to explain the problematic issue and analyze the source of error. In pair work or group work students cooperate, and complement each other's knowledge. That is why being corrected individually learners feel: a. 'comfortable'; b. 'good'; c. 'slightly embarrassed'

Figures 8 and 9 illustrate that students tolerate only individual correction from their peers. They treat it as something natural when a friend corrects their mistakes. They generally believe they can count on their friends and rely on their suggested solutions to some problems, whereas peer correction in front of the classroom has a negative connotation and evokes feelings of embarrassment or shame. 
Figure 9. Students' feelings towards individual peer correction

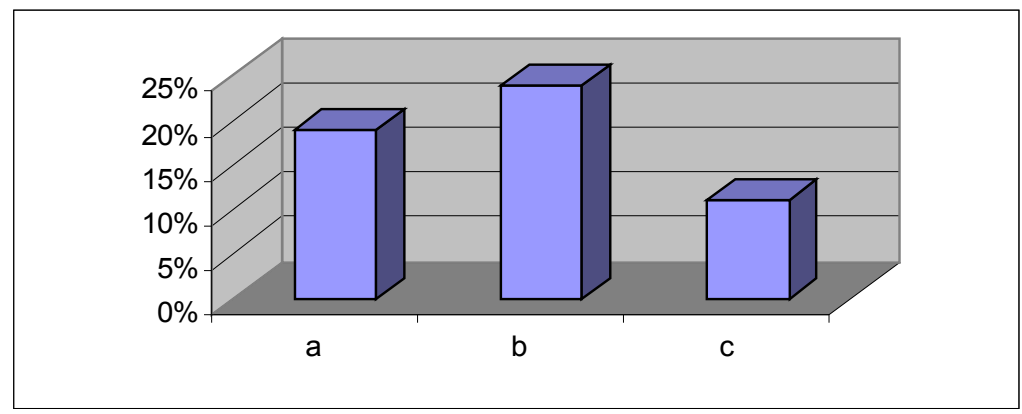

\section{Conclusions}

Errors are a natural part of developing fluency, either in the first or second language. The main aim of this work was to find out if learners appreciate error correction. The research results clearly indicate that students generally believe that making errors is one of the things they do while learning a foreign language. They agree that they can learn a lot from their mistakes. Almost $40 \%$ of the research subjects think that error correction is absolutely necessary, and a half of them see correction as very helpful. They value correction as a means of improvement. Most of the learners are not afraid of errors and treat them as something natural. However, almost a half of the subjects associate making a mistake with the feeling of guilt. They use an avoidance technique in order not to be laughed at when they make a mistake. Thus, errors should not be approached with hostility. Teachers should deal with learners' errors in a supportive and effective way.

Students definitely prefer teacher correction to any other kind of correction. The majority of pupils want to be corrected by someone in a superior position in the classroom, and they treat the teacher as an authority when it comes to error correction. The majority of students also claim that the teacher has great influence on their learning. They pay attention to a teacher's features as well as to his or her beliefs about learning. Most of the subjects claimed that their teacher motivated them by being very helpful and kind.

Peer correction appeared to be the least desirable correction technique. Although this method is believed to benefit learners in developing language awareness, very few learners want to accept criticism from their peers.

Correction itself is an extremely delicate and sensitive issue. Research shows that learners usually expect teachers to correct their errors and are not satisfied by teachers' responses which do not provide correction but merely indicate the error or express disapproval. Some of the students want to be corrected more than teachers themselves believe they should be. This willingness, however, is there as 
long as students feel that correction is the teacher's affective support, not any kind of punishment. Learners are aware that without correction they could have a false image of their language competence. If they were not corrected, they would believe their language is perfect. This assumption could leave them frustrated and disappointed when they discovered how wrong they were. Thus, correction appears to be necessary for the learning to take place.

All in all, in spite of various viewpoints on error treatment, it can be concluded that most present-day methodologists, such as Ellis (1994), Bartram (1991), or Zybert (1999), suggest a reasonable tolerance towards errors. This will prevent learners from developing inhibition or fear to communicate. It is assumed that errors will gradually disappear if progress is made in language learning.

The data obtained in the research answered many questions about learners corrective preferences, as well as their opinions about learning English. However, it would be useful to carry out further research among teachers, to get an idea of what their beliefs about correction techniques are, and which techniques are most frequently used by them.

The research shows that teenage learners expect the teacher to provide correction. They definitely prefer teacher correction than any other treatment of errors as he or she is regarded an authority in the classroom. Nonetheless, the teacher must remember that an adequate amount of self-correction and peer-correction can be beneficial for learners. Some students view peer correction as a way to show the class and the teacher how good they are. They try to dominate in the classroom, and look down on those with learning difficulties. On the other hand, poorer learners prefer to remain silent in order not to face the criticism from their peers which they cannot cope with. They want to avoid the embarrassment and shame. Therefore, the teacher has an important role to play during every lesson: create a pleasant atmosphere, encourage the shy students to practise their language, as well as do not let the most talkative ones impose their opinions and dominate on others. It can be done by means of various pair-work or group-work activities which allow even the introverted students to take active part in language tasks. Moreover, the teacher ought to introduce a balanced amount of peer- correction and self- correction. Before he asks students to correct themselves, he should provide some explanation about the source of an error, or give some clues how to repair it (Kosslyn, 1981; Ellis, 1994).

In addition, the research shows that learners consider the teacher as a crucial factor in their learning. Students value the teacher who is able to run interesting lessons, is kind and helpful towards them, and provides clear explanations. They also perceive the teacher as a person who is responsible for choosing a particular teaching method, which they find either challenging or de-motivating. Thus, teachers must consciously adopt such methods that will satisfy learners' expectations. The use of authentic materials, such as songs, newspaper articles, which bring up topics that are important for teenagers, 
games or films, can bring a pleasant change in the teaching routine. To conclude, teachers should realize that students' willingness to learn a second language depends significantly on their attitude and beliefs towards error treatment and foreign language learning in general.

\section{References}

Albanese, O. (1999). Children's story comprehension and teacher's story-telling. Psychology of Language and Communication, 3(1), 7-17.

Arabski, J. (1979). Errors as Indications of the Development of Interlanguage. Katowice: Uniwersytet Śląski.

Bartram, M., Walton, R. (1991). Correction: Mistake Management: A Positive Approach for Language Teachers. Hove: Language Teaching Publications.

Biederman, I. (1987). Recognition - by - components: A theory of human image understanding. Psychological Review, 94, 115-147.

Brala, M. M. (2002). Understanding language specificity: causes and consequences. Psychology of Language and Communication, 6(2), 33-46.

Chaudron, C. (1988). Second language classroom. Research on teaching and learning. Cambridge: Cambridge University Press.

Chomsky, N. A. (1987). Language in a psychological setting. Sophia Linguistica, 22, 1-73.

Corder, P. (1981). Error analysis and interlanguage. Oxford: Oxford University Press.

Cox, K., Eyre, J. (1999). A question of correction. English Teaching Professional, 12, 47-48.

Dunford, H. (1993). To correct or not to correct? Modern English Teacher, 3(2), 63-64.

Edge, J. (1989). Mistakes and correction. London: Longman.

Ellis, R. (1994). The study of second language acquisition. Oxford: Oxford University Press.

Higgins, E. T. (1987). Self-discrepancy. A theory relating self and affect. Psychological Review, 94, 319-340.

Jacobs, D. M., Michaels, C. F. (2007). Direct learning. Ecological Psychology, 19, 321-349.

Johnson, K.E. (1995). Understanding communication in second language classrooms. Cambridge: Cambridge University Press.

Kaye, P. (2000). Correcting mistakes: four ideas to increase palatability and effectiveness. Modern English Teacher, 9(2), 61-63.

Kosslyn, S. M. (1981). The medium and the message in mental imagery: A theory. Psychological Review, 88, 44-66.

Lightbown, P. M., Spada, N. (1993). How languages are learned. Oxford: Oxford University Press. 
Murray, S. (1999). Correct me if I'm wrong. Modern English Teacher, 8(3), 43-47.

Whorf, B. L. (1969). Language, thought, and reality. Cambridge: MIT Press.

Wierzbicka, A. (1980). Lingua mentalis: The semantics of natural language. Sydney: Academic Press.

Zybert, J. (1999). Errors in foreign language learning. The case of Polish learners of English. Warszawa: Uniwersytet Warszawski. 